\title{
Acute Traumatic Quadriplegia in Adults: Predictors of Acute in-Hospital Mortality
}

\author{
Khalid ALSALEH ${ }^{1}$, Drew BEDNAR ${ }^{2}$, Forough FARROKHYAR ${ }^{3}$ \\ ${ }^{1}$ King Saud University, Department of Orthopaedic Surgery, Riyadh, Saudi Arabia \\ ${ }^{2}$ McMaster University, Department of Orthopaedic Surgery, Hamilton, Canada \\ ${ }^{3}$ McMaster University, Department of Surgery, Hamilton, Canada
}

\section{ABSTRACT}

AIM: To assess the in-hospital mortality rate in adult patients suffering acute traumatic complete quadriplegia and determine the possible predictors of mortality in these patients.

MATERIAL and METHODS: A review of all complete quadriplegics treated from January 1996 through March 2004 in a regional spine injuries unit measuring in-hospital mortality and other factors that might contribute to increased mortality. Multivariate logistic regression analysis was performed to explore these possible predictors of mortality.

RESULTS: We identified 126 cases of cervical spinal cord injury treated at our hospital from January 1996 to March 2004 and identified only 62 cases of complete quadriplegia. Of 62 patients, 11 (17.7\%) died in the hospital. Age, gender, injury mechanism and medical co-morbidity showed only trends towards a higher mortality. Age and pre-injury medical co-morbidity were found to be significant independent predicting factors for mortality. Gender, mechanism of injury, neurological level and injury severity score were not the predictors of mortality in these patients.

CONCLUSION: Despite the limitations of the current evidence, advanced age and pre-existing medical co-morbidity are likely predictors of hospital mortality in the traumatic quadriplegia population.

KEYWORDS: Quadriplegia, Spinal Cord Injury, Mortality

\section{INTRODUCTION}

S pinal cord injury (SCl) is a devastating, extreme and frequently fatal trauma outcome of disturbing frequency. It is estimated that 10,000 cases occur annually in North America with an annual direct care cost of almost 10 billion dollars (8).

The mortality of SCl is historically high, being $85 \%$ in 1903 and still $60 \%-80 \%$ in 1946 . Advances in quadriplegia care -including improved standards of respiratory support, intermittent bladder catheterization, prophylactic skin care and medical prophylaxis of thromboembolism- saw this decrease to $2-4 \%$ by $1982(3,10,11,16)$.
Many SCl patients have incomplete cord injuries with significant distal motor function preservation and accordingly improved prognosis. The complete quadriplegic lacks all motor function below the neck and is at particular risk of respiratory compromise through loss of accessory respiratory muscles. The "high quad" or "pentaplegic" with $\mathrm{SCI}$ proximal to the takeoff of the phrenic nerves at C4 loses even diaphragmatic function and may require phrenic nerve pacing, become ventilator-dependent, or succumb with current 1-year mortality of approximately $28 \%$ (7).

We have reviewed the database of our hospital in the attempt to assess the rate of in-hospital mortality in these patients and to identify the possible risk factors for acute and sub-acute mortality. 


\section{MATERIAL and METHODS}

Our regional spine and trauma care unit has maintained a database including spinal cord injury patients since 1996. We treat only adult patients as cases aged 16 years or less are referred to the regional pediatric hospital and all injury cases of Injury Severity Score (ISS) >12 are recorded (2).

From the database we identified 126 cases of cervical SCI treated at our hospital from January 1996 to March 2004. After excluding cases that were dead on arrival, those initially treated elsewhere, patients having a neurological deficit prior to injury and incomplete spinal cord injuries, we identified 62 cases of complete quadriplegia in adults treated acutely at our institution.

Hospital charts were then reviewed to collect data on possible risk factors including age, sex, mechanism of injury, level of injury, ISS and pre-injury medical co-morbidity as quantified by the Charlson medical co-morbidity score (4). The Charlson score is the most extensively used and studied medical co-morbidity index and has been validated for its ability to predict general medical mortality. The Charlson co-morbidity Index is a 0 to 2 point analogue score where a perfectly healthy individual scores zero and increasing illness raises the patient's score.

Categorical data are reported as percentages and are compared using the chi-squared or Fisher's exact test. Continuous data are reported as median with standard deviation or median with minimum and maximum and compared using student t-test or Wilcoxon rank test if they were not normally distributed. Univariate logistic regression analysis was used to assess the predicting effect of each individual predicting variable. Finally, multivariable logistic regression analysis was performed to explore the predictors of mortality. Factors with $\mathrm{P}<0.1$ based on univariate analysis were entered in the final model. Odds ratios and 95\% confidence intervals $(\mathrm{Cl})$ and HosmerLemeshow statistics for goodness of calibration is reported. A p-value of 0.05 was considered for statistical analysis. SPSS statistical software (IBM-Armonk, New York, USA) was used for analysis.

\section{RESULTS}

Of 62 acute complete adult quadriplegics treated primarily at our institution during the study period, 49 (79\%) were males and $13(21 \%)$ were females with mean age of $45 \pm 21$ years. The mechanism of injury was motor vehicle accidents in $30(48.4 \%)$ patients, fall in $23(37.1 \%)$ patients and sport/ gunshots in nine (14.5\%) patients. The Charlson co-morbidity Index was zero in 42 (67.7) patients, 1 in 14 (22.6\%) and 2 in $6(9.7 \%)$. Of 62 patients, $51(82.3 \%)$ patients survived to discharge and 11 (17.7\%) died in the hospital (Table I).

Table II summarizes the univariate comparison of baseline characteristics between patients who survived and those who died. Patients who died were significantly older than those who survived [median=73 years (range=23-88) versus 37 years (range $=18-79), p<0.001$ ], respectively. Of the fatalities, six cases $(55 \%)$ were male and $5(45 \%)$ were female $(p=0.04)$. The ISS scores were similar between survived populations [median=25 (range=16-75)] and fatality population [median= 25 (range=16-75), $p=0.91$ ]. The mechanism of injury was associated with a higher mortality as 8 of 11 fatalities $(72.7 \%)$ were injured due to a fall, $3(27.3 \%)$ due to the motor vehicle accident $(p=0.02)$. Of the fatalities group, the Charlson comorbidity Index was zero in two (27.3\%) patients, 1 in 5 $(45.5 \%)$ patients and 2 in $4(36.4 \%)(p<0.001)$. The "high quad" or "pentaplegic" population was at higher risk of mortality. Of 11 patients who died, five (45.5\%) were with preserved levels

Table I: Causes and Circumstances of Death

\begin{tabular}{|c|c|c|c|c|c|}
\hline Cause of death & Age (years) & Sex & LOS (days) & Spared level & Location \& code status \\
\hline Anoxic brain damage & 23 & $M$ & 2 & $\mathrm{C} 2$ & ICU, care withdrawn \\
\hline Multiple organ failure & 44 & $\mathrm{M}$ & 2 & C3 & ICU, care withdrawn \\
\hline UTI, sepsis & 57 & $\mathrm{~F}$ & 24 & C5 & Ward, DNR \\
\hline Pneumonia, Sepsis & 62 & M & 32 & C6 & ICU, care withdrawn \\
\hline Anoxic brain damage & 72 & M & 3 & $\mathrm{C} 2$ & ICU, care withdrawn \\
\hline Bradycardia, CHF & 73 & $\mathrm{~F}$ & 9 & $\mathrm{C} 4$ & Ward, comfort, DNR \\
\hline Respiratory failure & 79 & M & 3 & $\mathrm{C} 7$ & ICU, care withdrawn \\
\hline Ventilator dependent & 81 & $\mathrm{~F}$ & 36 & C5 & ICU, care withdrawn \\
\hline Unknown & 87 & M & 2 & $\mathrm{C} 6$ & Ward, DNR \\
\hline Ventilator dependent & 87 & $\mathrm{~F}$ & 2 & $\mathrm{C} 7$ & ICU, care withdrawn \\
\hline Ventilator dependent & 88 & $\mathrm{~F}$ & 18 & C3 & ICU, care withdrawn \\
\hline
\end{tabular}

ICU: Intensive care unit, UTI: Urinary tract infection, LOS: Length of stay, DNR: Do not resuscitate, CHF: Congestive heart failure, M: Male, F: Female. 
C2, C3 or C4 compared with six (54.5\%) patients who spared at $\mathrm{C} 5$ or distally $(p=0.27)$. While the study group as a whole was clustered in the mid-subaxial levels, fatalities were evenly distributed (Table III). Further analysis according to length of stay was done and the patients were categorized into early (<7days) and late deaths (7 days or more). Analyzed as such, there was no significant difference in the age (65.3 mean age for early death versus 72.2 age for late death) or the neurologic level between the two groups ( $p>0.05)$.

Using multivariate analysis, the Charlson medical co-morbidity index $[\mathrm{OR}=4.01 ; 95 \% \mathrm{Cl}=1.20,13.44]$ and age $[\mathrm{OR}=1.06 ; 95 \%$ $\mathrm{Cl}=1.01-1.11]$ were the independent predictors of mortality with a $\mathrm{p}$ value of 0.128 for Hosmer-Lemeshow statistics indicating a moderately good calibration.

\section{DISCUSSION}

The present study was a retrospective review of patients treated for acute traumatic quadriplegia. The in-hospital mortality was $18 \%$ in 62 patients. This figure is similar to other reports in the more recent literature $(5,6,12-15,17,18)$. In the systematic review and meta-analysis by van Middendorp et al. of these cases; the pooled mortality rate was $22 \%$ (18). Age and the Charlson co-morbidity index were the independent predictors of mortality in this study. Age and preserved neurological level have been presented as predictors of early mortality in the quadriplegic population based on data from retrospective cohort studies presented in the 1970's and 1980's $(7,10,11,16)$, most of which were not focused on complete paralysis but included patients with variable degrees of neurological sparing. With regards to neurologic level, the recent publication by Daneshvar et al. found neurologic level above $\mathrm{C} 4$ to be the most important factor for mortality (6). As for age, previous publications have had conflicting results (1). Olerud et al. (15) and Liang et al. (13) found age to be a significant factor associated with increased mortality while Damadi et al.-for example- did not (5). The current study found that both these factors were not independent risk factors for early death in acute traumatic quadriplegia. The ISS (2) is an important predictor of mortality after multiple traumas, but it was not found to be so in our acute quadriplegia population. This is not consistent with some of the available reports where there was direct correlation between the ISS and mortality (5). The Charlson co-morbidity Index has not, to our knowledge, been previously applied to the trauma quadriplegia population except once in the study by Furlan et al. where a direct correlation between the Charlson index score and mortality was found (9).

The current study has certain limitations to the current findings due to the inherent biases applied to observational studies particularly in retrospective designs. It is a retrospective chart review and there is the possibility of inaccuracy and missing information. For example, the exact cause of death was not uniformly recorded and so direct linkage to specific

Table II: Univariate Comparisons of Baseline Characteristics

\begin{tabular}{|c|c|c|c|c|c|}
\hline & \multicolumn{2}{|c|}{ Survived $(n=51)$} & \multicolumn{2}{|c|}{ Died $(n=11)$} & p value \\
\hline \multicolumn{6}{|l|}{ Gender } \\
\hline Female & 8 & 15.7 & 5 & 45.5 & 0.043 \\
\hline \multicolumn{6}{|l|}{ Mechanism of injury } \\
\hline Sports/gunshots & 9 & 17.6 & 0 & 0 & 0.021 \\
\hline \multicolumn{6}{|l|}{ Charlson Comorbidity Index } \\
\hline 0 & 40 & 78.4 & 2 & 18.2 & \\
\hline 1 & 9 & 17.6 & 5 & 45.5 & \\
\hline
\end{tabular}

Table III: Preserved Neurological Level (n)

\begin{tabular}{lccccccc}
\hline & C2 & C3 & C4 & C5 & C6 & C7 \\
\hline Survivors & 2 & 2 & 9 & 20 & 13 & 5 \\
\hline Deaths & 2 & 2 & 1 & 2 & 2 & 2 \\
\hline
\end{tabular}


co-morbidities was not possible. The possibility of inaccuracy and missing data in the current study was likely minimal due to the objectivity of the outcome measure and nature of the patient population condition. The study is however underpowered due to the small sample size to detect the true differences. In addition to that: this study presents a heterogeneous group of patients treated using different treatment modalities. Some underwent surgery while most were treated by closed reduction \& external immobilization as they we not stable enough to undergo a definitive operative procedure to stabilize the spine. Diagnostic modalities were not uniform either. Generalizability based on this study sample is-therefore affected. Information from magnetic resonance imaging (MRI) could have added more data with regards to the severity of the damage to the spinal cord and further correlation could have been done to see any effect on mortality. Access to MRI at the time was quite limited and it was not part of the treatment protocol for every spinal cord injury patient.

\section{CONCLUSION}

Pre-injury medical co-morbidity is an important predictor of mortality in acute traumatic quadriplegia. Despite the limitations of the current study, the aggressive treatment and support of elderly and high-risk patients is highly recommended. The development of multicenter traumatic quadriplegia registries should be encouraged to fully examine the possible predictors of mortality in these patients and ascertain whether their outcomes can be improved.

\section{REFERENCES}

1. Alander $\mathrm{DH}$, Andreychik DA, Stauffer EH: Early outcome in cervical spinal cord injured patients older than 50 years of age. Spine 19: 2299-2301, 1994

2. Baker SP, O'Neill B, Haddon W Jr, Long WB: The injury severity score: A method for describing patients with multiple injuries and evaluating emergency care. J Trauma 14: 187-196, 1974

3. Bohlman $\mathrm{HH}$ : Acute fractures and dislocations of the cervical spine. An analysis of three hundred hospitalized patients and review of the literature. J Bone Joint Surg Am 61(8): 11191142, 1979

4. Charlson ME, Pompei P, Ales KL, MacKenzie CR: A new method of classifying prognostic comorbidity in longitudinal studies: Development and validation. J Chronic Dis 40: 373383, 1987
5. Damadi AA, Saxe AW, Fath JJ, Apelgren KN: Cervical spine fractures in patients 65 years or older: A 3-year experience at a level I trauma center. J Trauma 64(3): 745-748, 2008

6. Daneshvar P, Roffey DM, Brikeet YA, Tsai EC, Bailey CS, Wai EK: Spinal cord injuries related to cervical spine fractures in elderly patients: Factors affecting mortality. Spine J 13(8): 862-866, 2013

7. Daverat P, Gagnon M, Dartigues JF, Mazaux JM, Barat M: Initial factors predicting survival in patients with a spinal cord injury. Paraplegia 52: 403-406, 1989

8. Fehlings MG, Tator $\mathrm{CH}$ : An evidence-based review of surgical decompression for acute spinal cord injury: Rationale, indications, and timing based on experimental and clinical studies. J Neurosurg 91 (Spine 1): 1-11, 1999

9. Furlan JC, Kattail D, Fehlings MG: The impact of co-morbidities on age-related differences in mortality after traumatic spinal cord injury. J Neurotrauma 26: 1361-1367, 2009

10. Geisler WO, Jousse AT, Wynne-Jones M, Breithaupt D: Survival in traumatic spinal cord injury. Paraplegia 21: 364373, 1983

11. Hardy AG: Survival periods in traumatic quadriplegia. Paraplegia 14: 41-46, 1976

12. Krassioukov AV, Furlan JC, Fehlings MG: Medical comorbidities, secondary complications, and mortality in elderly with acute spinal cord injury. J Neurotrauma 20(4): 391-399, 2003

13. Liang HW, Wang YH, Lin YN, Wang JD, Jang Y: Impact of age on the injury pattern and survival of people with cervical cord injuries. Spinal Cord 39: 375-380, 2001

14. Majercik S, Tashjian RZ, Biffl WL, Harrington DT, Cioffi WG: Halo vest immobilization in the elderly: A death sentence? J Trauma 59: 350-256, 2005

15. Olerud C, Andersson S, Svensson B, Bring J: Cervical spine fractures in the elderly: Factors influencing survival in 65 cases. Acta Orthop Scand 70(5): 509-513, 1999

16. Ravichandran G, Silver JR: Survival following traumatic quadriplegia. Paraplegia 20: 264-269, 1982

17. Tashjian RZ, Majercik S, Biffl WL, Palumbo MA, Cioffi WG: Halo-vest immobilization increases early morbidity and mortality in elderly odontoid fractures. J Trauma 60: 199-203, 2006

18. van Middendorp JJ, Albert TJ, Veth RP, Hosman AJ: Methodological systematic review: Mortality in elderly patients with cervical spine injury: A critical appraisal of the reporting of baseline characteristics, follow-up, cause of death, and analysis of risk factors. Spine 35(10): 1079-1087, 2010 